\title{
Like a Chameleon: Resilience among Self-Identified Latinx Mixed Adults
}

\author{
Melissa Morgan ${ }^{a 1}{ }^{(0)}$, Erika Noriega Pigg ${ }^{b}{ }^{\mathbb{C}}$, Andrés Consoli ${ }^{\sqrt{ }}$, \\ Daniella Pavone ${ }^{\mathrm{a}} \mathbb{C}, \boldsymbol{\&}$ Daniel Meza ${ }^{\mathrm{c}}{ }^{2}$
}

\author{
University of California, Santa Barbara, United States of America a, Kaiser \\ Permanente Psychiatry Department, Santa Rosa, United States of America \\ ${ }^{\mathrm{b}}$; University of California, Berkeley, United States of America ${ }^{\mathrm{c}}$
}

\begin{abstract}
The experiences of coping with adversities among nine Latinx adult participants (six females, three males) who self-identified as ethnically mixed were explored through semi-structured, individual interviews. Participants identified a range of challenges related to their mixed identity status, including experiences of discrimination and instances of identity conflict. Participants specified methods of overcoming challenges they faced as mixed individuals including seeking cultural commonalities, finding strength and pride within their cultures, exercising acceptance, and emphasizing aspects of oneself depending on contexts and circumstances. Finally, participants discussed resilience related growth experiences related to their mixed identity characterized by improved relationships and self-esteem. The findings provide detailed information about resilience for these mixed Latinx individuals that may be helpful in better understanding and serving others who identify similarly.
\end{abstract}

Keywords

Mixed identity; Latinx; resilience

\section{RESUMEN}

Las experiencias de enfrentar las adversidades entre nueve adultxs latinxs (seis mujeres y tres hombres) quienes se autoidentificaron como personas de identidad étnica mixta fueron exploradas en entrevistas individuales semiestructuradas. Lxs participantes identificaron una serie de desafíos relacionados con su identidad mixta, incluyendo experiencias de discriminación e instancias de conflicto de identidad. Lxs participantes especificaron algunos métodos para superar los desafíos que enfrentan como personas mixtas incluyendo la búsqueda de coincidencias culturales, encontrando fuerza y orgullo dentro de sus culturas, ejerciendo aceptación, y enfatizando aspectos de unx mismx dependiendo de contextos y circunstancias. Finalmente, lxs participantes compartieron experiencias de crecimiento y resiliencia relacionadas con su identidad mixta y las cuales se caracterizaron por mejores relaciones y autoestima. Los hallazgos proporcionan información detallada sobre la capacidad de recuperación en estas personas latinas de identidad mixta que pueden ser útil para comprender mejor y servir a otras personas que se identifican de manera similar.

Palabras claves

Identidad mixta; Latinx; resiliencia

\footnotetext{
1 Correspondence about this article should be addressed to Melissa Morgan : $\underline{\text { mmorgan@education.ucsb.edu }}$

2 Conflicts of Interest: The authors declare that the research was conducted in the absence of any commercial or financial relationships that could be construed as a potential conflict of interest.
} 
Como un camaleón: la resiliencia entre los adultos mixtos autoidentificados como latinos

In 2000, and for the first time in the history of the United States Census, respondants were given the opportunity to identify with more than one race. This change, which came about after much controversy (Pew Research Center, 2015) has officially allowed individuals to self-identify with multiple racial and/or ethnic categories (Negy et al., 2004), thereby highlighting a growing group of people who identify as "mixed"," including Latinxs.

The cultural, ethnic, and racial diversity of the Latinx population, or mestizaje, is based on colonizing processes and the blending of Spanish and indigenous peoples (Vasconcelos, 1925; 1979) therefore almost all individuals identifying as Latinx today are actually of mixed backgrounds, and many choose to identify as such (Pew Research Center, 2015). However, the debate on what categories to use in the census has been a complicated one, and many remain dissatisfied with the categories available; thus in common usage people often create their own self-labels, based on culture, nationality, ethnicity and/or race (Anderson et al., 2004).

What has been designated as mixed identity has changed depending on the time period (Shih \& Sanchez, 2009). For example, many mixed individuals within the U.S. Latinx population identify as such given the history of colonization within Latin American countries, in which the miscegenation of indigenous, African, and European heritage peoples occurred (Jackson et al., 2013). Typically, the literature has focused on other mixed populations, such as Black and White (Romo, 2011), although studies conducted by the Pew Research Center in 2015 found that in the U.S., self-identified multiracial people also include "Hispanic heritage" and another race.

\section{Challenges and Adjustment for Mixed Individuals}

Research shows that mixed individuals face multiple challenges such as limited social recognition, discrimination, social isolation, disapproval from family members,

${ }^{3}$ Many terms have been used to describe individuals with this identification, however in this article the term 'mixed' denotes people who self-identify as being multiracial, multiethnic or multi-cultural; however, the literature review in the article retains the terms that other researchers used to describe mixed individuals in their studies. 
and exclusion from neighborhoods and communities (Brown, 1990; Shih \& Sanchez, 2005). While monoethnic or monoracial minorities also share many of these difficulties, there is some indication that mixed individuals experience unique challenges such as others' disbelief regarding racial heritage, multiracial discrimination and challenges with racial identity (Salahuddin \& O’Brien, 2011). In particular, given historically defined U.S. racial groups, mixed race people may experience difficulties fitting in with any racial/ethnic identity group (Edwards \& Pedrotti, 2008; Salahuddin \& O'Brien, 2011; Shih \& Sanchez, 2005). As with racism and marginalization experienced by minority groups (Brown, Meadows, \& Elder, 2007; Sellers et al., 2006), monoracism, or the societal pressure to identify with one racial or ethnic group (Jackson, 2012; Johnston \& Nadal, 2010), can ultimately affect the mental health and wellbeing of mixed individuals (Jackson et al., 2013).

Individuals who identify as mixed Latinxs may face even more extreme stressors given anti-immigration sentiments (Market, 2010). Such discrimination may also lead to renouncing affiliation with groups associated with one's own identity, resulting in further isolation and alienation (Stephan \& Stephan, 2000). Such disowning of parts of one's identity, particularly by force, may negatively affect one's sense of belonging and selfesteem. Identity development in general has been found to be more difficult and confusing for multiracial individuals than for monoracial individuals (Shih \& Sanchez, 2005), and some research suggests higher suicidality in mixed ancestry Latinx youth (Olvera, 2001). For Latinx mixed individuals specifically, as for other Latinxs, additional challenges may stem from their history of colonization, difficulties surrounding family migration to the U.S., and acculturation difficulties (Finch \& Vega, 2003).

\section{Resilience and Mixed Individuals}

Despite the existence of significant challenges for many mixed adults, up to $19 \%$ of multiracial individuals report feeling their mixed identity has been advantageous (Pew Research Center, 2015). A growing body of literature has focused on the strengths of mixed Latinx identification (Jackson, 2012; Jackson et al., 2013; Shih \& Sanchez, 2009). For example, some research suggests that self-identified multiracial individuals have well-developed abilities to cope with adversities by being exceptionally adaptive and able to act as social "chameleons" (Miville et al., 2005) in encounters with other individuals of differing backgrounds. This adaptability may allow for more extensive cross-cultural 
relationships (Salahuddin \& O’Brien, 2011) as well as heightened multicultural sensitivity (Miville et al., 2005; Shih \& Sanchez, 2005). Encompassed within this phenomenon is an ability to be more perceptive and receptive to identifying social cues as they regularly come into contact with people from different racial or ethnic groups (Miville et al., 2005; Salahuddin \& O'Brien, 2011). This ability to adapt and fit into different sociocultural groups has also been described as "flexible ethnicity," or the ability to move easily between different racial/ethnic groups (Vasquez, 2010, p. 46). In the case of Mexican-Americans, for example, who identified as multi-ethnic Mexican and White Non-Hispanic, participants described such characteristics as allowing them to integrate facets of more than one culture into their lifestyles (Jiménez, 2004). This flexibility may manifest in different periods of one's life, or in different settings (Jackson, 2012; Roquemore et al., 2009).

Resilience, defined as being able to overcome adversity and return to normal development (Garmezy, 1993; Rutter, 1987), may be particularly important to understand for mixed individuals, given their unique challenges and circumstances. Resilience has been found to be multidimensional, encompassing the ability to respond well to challenging situations by drawing from coping skills, virtues, and social support networks (Luthar et al., 2000). While resilience among mixed individuals specifically has received minimal research attention, some findings indicate that adults who identify as multiracial report greater wellbeing than monoracially identified individuals (Binning et al., 2009; Sanchez et al., 2009). Mixed individuals with families who have worldviews consistent with their ethnic beliefs, values, customs, and expectations have been found to have greater wellbeing (McCubbin, 2006). For example, Latinx individuals have been found to possess certain strengths related to cultural values that contribute to resilience such as perseverance (Morgan Consoli et al, 2015), spirituality (Farley et al., 2005), and familismo (Morgan Consoli et al, 2011; Llamas \& Morgan Consoli, 2012; Zambrana et al., 1997). Similarly, flexible identities, being strategic about relationships, and finding culturally affirming spaces have been found to be helpful processes contributing to resilience in mixed adults (Jackson et al., 2013).

The current qualitative study explores the processes of resilience in Latinxs who self-identify as mixed. The specific challenges and methods of overcoming those challenges, as well as the gains obtained from this process are investigated with the aim of better understanding the "picture" of resilience as experienced by some Mixed Latinx individuals. 


\section{Method}

\section{Researchers}

The research team consisted of a female, counseling psychology faculty member who self-identifies as mixed (Latina and European); a female, doctoral student who selfidentifies as mestiza (Latin American woman of mixed race); a male, counseling psychology faculty member who self-identifies as mixed (Latino and European); a male, doctoral student who self-identifies as mixed (Chicano and European), and a female, undergraduate research assistant who self-identifies as mixed (Peruvian and White). All were affiliated with the counseling psychology program at a West Coast university and were trained in a social justice, strengths-based orientation. All began the project believing that resilience is possible for all individuals, given the right circumstances. Four of the team members spoke both English and Spanish.

\section{Participants}

Participants were recruited from the local community through social media and fliers. Inclusion criteria involved self-identifying as Latinx and mixed cultural or ethnic background, feeling that they had successfully overcome adversities, and being age 18 or older. These criteria were chosen in an effort to honor participants' self-identification, as they identify in "real-life," not as they may be forced to do in a census or as is discussed in the academic literature. Because qualitative research focuses on understanding the experience itself (i.e., overcoming adversity among individuals who identify as mixed; Polkinghorne, 2005), it was necessary to select individuals who could richly describe this experience. Therefore, purposive sampling was used to locate individuals who could potentially provide exemplars of such an experience (Patton, 1990; Polkinghorne, 2005). Specifically, we publicized this investigation through social media posts and by placing flyers in the community. Nine participants (6 females, 3 males) were recruited for the study, in accordance with the Consensual Qualitative Research (CQR) sample size recommendation of at least eight participants (Hill et al., 2005). Participants ranged from 20 to 64-years of age. Reported mixed identification for the participants encompassed a variety of mixed racial, ethnic, and cultural backgrounds as reflected in their responses to an open-ended item self-defining their mixed identification. Three of the participants were bilingual (i.e., English and Spanish), and used Spanish in portions of their interviews 
with their Spanish speaking interviewer. All participants were assigned pseudonyms to protect confidentiality and identifications below are reported as participants selfidentified.

Ashley, 23, self-identified as a Latina, Russian, and African American female, with her Russian and Latina cultures having the most influence in her daily life. She had taken courses at the community college level and was working full-time.

Carlos, 26, self-identified as a Latino, White, African American, and Armenian male. Carlos reported that his Latino and White heritages have had the most influence in his daily life. He worked as a fitness instructor at various companies and had earned an undergraduate degree.

Gloria, 28, self-identified as a Mexican and White female. Gloria reported that both her Mexican and White heritage have equal impact on her daily life. She had taken courses at the community college level and was a "stay-at-home mother."

José. 19, self-identified as a White, Mexican, and Guatemalan male. José reported that his Latino identities influenced his life the most. He was a college student at the time of the interview.

Julia, 22, self-identified as a White and Mexican female. She reported that her Mexican and White identities are reflected equally in her life. She was a graduating university senior at the time of the interview.

Michelle, 38, self-identified as a European-White, Italian, and Mexican female. Michelle reported that she is most influenced by her European-White and Italian heritages. She had earned an Associate's Degree and was working full-time at the time of the interview.

Ricardo, 20, self-identified as a Mexican, American, Spanish, and French (Basque) male. Ricardo reported that his Mexican heritage influenced his daily life the most, with his American culture also having a strong impact. He was enrolled at a university as a full-time student at the time of the interview.

Rosa, 64, self-identified as an American, African American, and Puerto Rican female. Although Rosa talked most about her ethnic minority identities, she indicated that she feels most influenced by her (overall) "American identity." She had taken courses at the community college level and was working full-time at the time of the interview.

Yvonne, 30, self-identified as an Italian and Mexican female. Yvonne reported that she experiences both cultural identities as influencing her daily life. She had graduated from a Master's program, and worked full-time at the time of the interview. 


\section{Procedures}

Eligible participants were invited to the interview at a convenient, reasonably quiet and private location of their choosing (e.g., quiet coffee shop, office, or home). The researchers addressed privacy concerns by allowing interviewees to designate the location for the interview, and suggested relatively quiet, uncrowded locations. Participants were asked to complete a brief demographic questionnaire and the Resilience Scale (Wagnild \& Young, 1993), which both served as background information and context for interpreting the data.

All participants consented to be audio-recorded. Interviews lasted approximately one hour and were transcribed verbatim by a trained research assistant. When given a choice between English and Spanish, all interviewees preferred to be interviewed in English, although they sometimes interspersed some Spanish words. All participants were given a $\$ 10$ gift card to a local store in appreciation for their participation.

\section{Instruments}

Demographic Questionnaire. The demographic questionnaire asked about sex, age, ethnicity, educational level, marital status, number of children, religion, generational status and income level, as well as two questions about which cultural, racial, or ethnic identities they feel most influence their lives.

Resilience Scale. The Resilience Scale (RS; Wagnild \& Young, 1993) is a 25item scale, measuring individual resilience as defined by positive personality characteristics that enhance individual adaptation and predict quality-of-life satisfaction. RS items are positively worded, and responses are given on a Likert-type scale ranging from 1 (agree) to 7 (disagree). Scores range from 25 to 175 with higher scores indicating higher resilience. RS scores have been highly correlated with measures of morale, life satisfaction, and negatively correlated with depression. Strong internal reliability $(r=.76-$ .91), construct validity, and concurrent validity have been reported for the RS. It has been used successfully with various ethnic minority populations including Latinx (Abiola \& Udofia, 2011; Joseph \& Maltby, 2014; Lindenberg et al., 2002; Llamas \& Morgan Consoli, 2012), African American, American Indian, and Asian populations (Wagnild, 2009). The scale was given to participants for selection purposes only and to triangulate the individual's self-reporting of resilience, as an additional source of information about participants' self-perception of their own resilience. 
Semi-structured interview. The semi-structured interview included 6 core questions about adversities faced, methods of overcoming the adversities, and outcomes specific to self-identified mixed individuals. Six follow-up prompts were used for clarification or to obtain further information. Semi-structured interview questions were piloted on individuals that also self-identified as Latinx and mixed (see Appendix 1).

\section{Data Analysis}

The CQR method was used to analyze interview transcripts (Hill et al., 2005; Hill, Thompson, \& Williams, 1997). CQR has been recommended for multicultural research, for exploring less researched constructs, and for theory building (Haverkamp \& Young, 2007; Hill et al., 1997). This approach is primarily constructivist, recognizing multiple, and equally valid realities and conceptualizations of truth, with some aspects of postpositivism. Epistemological perspectives in $\mathrm{CQR}$ combine both constructivist and postpositivist perspectives, seeing both researcher and participant as having mutual influence on each other (constructivist), while also viewing the role of the researcher as a reporter of participant beliefs who employs standard procedures across participants (postpositivist). Axiology in CQR also holds both constructivist and postpositivist perspectives in recognizing the researcher's experience and lens as necessary in interpretation (constructivist), while minimizing bias through consensus and auditors (postpositivist). The rhetorical structure used to present $\mathrm{CQR}$ research is primarily postpositivist as data is reported in the third person with minimal interpretation (Hill et al., 1997). The procedure for CQR includes open-ended semi-structured interviews, multiple analysis team members, or judges, for the purpose of encouraging multiple perspectives; consensus in interpreting meaning of the data, and at least one auditor to review the coding scheme and minimize group think (Hill et al., 1997; Hill et al., 2005).

The analysis began with all research team members meeting to discuss preconceived notions about the study topic prior to conducting analysis. All team members expected that research participants would experience unique circumstances and challenges relevant to their mixed Latinx identities. It was also generally believed that participants would demonstrate resilience by overcoming challenges using unique strengths common for mixed people. The interview transcripts were coded separately by three analysis team members identifying major data domains (i.e., topic areas) and core ideas (i.e., abstracts or summaries). Members reconvened, after independently coding to 
discuss the identified domains and core ideas until they reached consensus, then the coding was discussed together over multiple meetings until consensus was reached as to which domains and core ideas best captured the participants' responses. During coding, members kept team process notes in order to track any decisions about domains and themes. Additionally, team members actively worked towards equalizing power differentials as they took turns in leading analysis discussions (Heppner et al., 2016). Hill and colleagues $(1997 ; 2005)$ highlight the importance of auditors and member checks. The first author served as an internal auditor during analysis sessions to monitor power differentials, groupthink, and adherence to process among the analysis team. When all relevant data had been accounted for in the coding scheme, it was submitted to an external auditor for review. The external auditor was a counseling psychologist from another university who identifies as a female, an immigrant from Eastern Europe, and who has been trained in a social justice perspective and conducts research on minority populations and cross-cultural issues. She has extensive experience in qualitative research. Suggestions made by the external auditor were considered and incorporated where deemed appropriate by the analysis team. The rigorous consensus procedure, taking process notes throughout, and the use of internal and external auditors helped to achieve data trustworthiness. Rich, descriptive quotes from participants illustrated each category, demonstrating credibility. The final result was a coding scheme that incorporated all relevant findings in domains and categories.

All team members were trained in $\mathrm{CQR}$ analysis by the first author, including educating members on core concepts, methodology, and the theoretical underpinnings of CQR. All members except one had previous experience using this approach.

\section{Results}

\section{Resilience Scale}

All participant scores ranged from "moderately high" to "very high." According to the scale developers, these scores indicated that all participants were able to selfmanage stress, maintain self-confidence, and remain motivated to keep going when faced with adversities (Wagnild \& Young, 1993), which was consistent with their self-report upon screening for the study and in their interviews. Moreover, the scale scores gave further context to the interpretation of the qualitative results. 


\section{Themes}

The domains identified include Challenges, Methods of Overcoming, and Growth. Consistent with CQR methodology, labels were used to indicate representativeness of responses: General (most or several) described categories applying to 8 or 9 cases, Typical (some) for those with 5 to 7 cases, or Variant (few) included 2 to 4 cases (Hill et al., 1997). Categories that had only one case were excluded. See Table 1 for domains, categories, and frequencies.

Challenges related to mixed identity. This domain was defined as participants' experiences with difficult events that occurred in their lives in relation to having a mixed Latinx identity: Cultural Marginalization, Identity Conflict, and Discrimination.

Cultural Marginalization (general frequency) was coded when participants described a situation in which they were judged for being "too much" of or "not enough" of one of their identities or when their identity was not understood. An example follows:

I was made fun of by my cousins, they would call me white girl and yeah... it was hard but... I fought back (laughing). My grandpa was like, oh just ignore them... and I have to bring this up, I remember my cousin, me and him are the same age, we're 30 now. But we grew up kind of... he got heavily into the gang. And one time we were playing run from the cops, and I was following him (laughs) and he was like jumping over fences and I was like running after him and I got caught on a fence, and I'm like hanging there, and they're like laughing at me, like you're white, you don't know how to run from the cops. (Yvonne)

Rosa stated:

That was the time, that I realized that, 'what am I?' Ya know, what am I? What am I really? ... But I know about my culture, I know about my Puerto Rican heritage. I know because, I will say, 'I'm Puerto Rican,' but you're only Puerto Rican if you're born in Puerto Rico, okay. So I say, 'Yo soy de raza puertorriqueña.' I said because I have to, my father used to tell me, 'you're American, that's it.' And my last name is (Spanish surname). And then I'd go (full name including Spanish and English surnames), (laughing) and they'd go what? 'Cause I'm bilingual.

In these examples, participants talked about experiencing a moment of rejection by others for not meeting a social standard in regards to what it means to be Latinx causing them to be dismissed for their multiple heritage background. 
Identity Conflict (variant frequency) was defined as feeling different and "torn" as a result of identifying as "mixed." Participants shared having variable and conflicted feelings about their racial/cultural identity. For example, Carlos stated:

In junior high I went through a little identity crisis in the sense that, I was in Middle School in (large west coast city) and they have a really big Latino population, and they have a really big Armenian population. And at the time, and I hate saying this, and I haven't said it too often, at the time I was torn between who do I go with... so I was in seventh and eighth grade I was torn between my Latino and my Armenian side and I knew more Spanish and in general I just had more exposure to the Latino culture, so I felt more comfortable there. Ya know, so sometimes you get called out, be like "Wait a minute", cause my last name is (Armenian surname). So, so their like "Aren't you half Armenian?' and sometimes I found myself, "No, no, no, not at all".

Rosa stated:

I definitely had a negative self-image. And I felt like ya know, I knew every person in high school... you know the jocks, the nerds, ya know the cool kids, the not cool kids, I mean I knew everybody, I had my hand in every group. I never clung to one group and I viewed that as being like ya know weird someway, viewed that as being kinda like "what the hell is wrong with me," I can't identify with one.

Based on these recollections, participants shared that being both Latinx and mixed led to the experience of feeling uncomfortable with embracing all of their identity. They reported a sense of being different from others, which led to some distress.

Discrimination (variant frequency) was defined as experiencing prejudicial treatment based on perceived racial/ethnic identity. The following are examples:

Yeah, they're (extended family) associating me as different, and I still think they do, to tell you the truth. I think they blame me a lot for not coming around. But they didn't understand that my grandparents had a lot to do with that, they... I couldn't always be on that side. And I did go as much as I could, but yeah we grew up in like two different, yeah it was two different worlds. Two different worlds, completely. (Yvonne)

Michelle stated:

All the chola girls used to want to beat me up because they said I was "whitewashed" because I didn't know Spanish fluently, and so they would bully me. So I went from one extreme from being like a "wetback, beaner" when I was little, to being "whitewashed" in high school, and being bullied by the chola girls...they were just mean... I 
got jumped one time by all the chola girls...they were rejecting me. I thought it was even worse to be rejected by your own, like your own culture.

For some, awareness of such "differentness" highlighted a sense of not belonging to either group:

I ask them what are you and they say, "I'm American." I understand to a certain extent too but even in Mexico I was still a Basque, a French Basque, and then in Basque country, if I'm there, I'm still a Mexican even though I'm a Basque. (Ricardo)

Methods of overcoming. Participants discussed mechanisms or ways of working through the difficult challenges associated with being mixed Latinx. Among those ways of overcoming specifically attributed to being mixed Latinx, participants described experiences that were coded as Cultural Connectivity, Use of Culture, Teaching Opportunities, Acceptance, Chameleon Effect, and Affiliation.

Cultural Connectivity (general frequency) was defined as the ability to find commonalities among their different cultures in order to overcome adversities. An example in which Carlos was able to connect with his cultures includes a moment when both sides of his family were engaged in a game of soccer. Carlos discussed that prior to this moment he was unaware that his Armenian father was actually a renowned soccer player in his native country, as he had associated soccer as a sport related only to his Latino heritage. He stated:

Sometimes we'd be like messing around at the park, so we'd have celebrations of our Latino side, so ya know we, ya know, how they do, the makeshift games in the park...so my Dad would play and he'd show all the Latinos how the Armenians did it, I was like 'Yeah, let's go!' (Carlos)

Somewhat similarly, the following response illustrates how Ashley also believed that Use of Culture (Typical frequency), specifically values within Latinx and/or other culture, was beneficial in experiencing resilience:

I don't ever wanna lose my culture and just lose where I came from because I like it, I like the whole being family oriented, being open, being involved whether it's a good time or like a tough time and stuff. Like I don't ever wanna lose that because it's like difficult...it just seems whack.

In Teaching Opportunities (typical frequency), defined as educating others about mixed identity, some participants noted that they liked to teach and had taught others about what it is to be multicultural or identify with multiple cultures. This included educating their own family members. As an example, Julia shared her passion to teach 
others when confronted with prejudice or ignorance regarding her mixed Latina identity and the importance of imparting a greater perspective on this matter:

I'll try to educate them... I just tell them what we learn in class. Like we all come from different areas and I can still be Mexican even if I'm half and I can still identify as Mexican even though I look white. I still identify as Mexican... Just using like different tools and learning about being mixed and having (pause) different cultures in school and things like that. It's just really helpful. And I think that the more (pause) the more people take these types of classes, they understand more.

Ricardo stated what he wished people would learn about being of mixed heritage, "I think people should be aware of their multicultural identity. I think in your study I hope that you can incorporate that being multicultural is a beautiful thing. It's like I said it's a portion, a concept, a part of your identity."

Acceptance (typical frequency) was defined as feeling accepted for who one is in certain environments. This concept is illustrated by the following participant:

Everyone has a different personality here, a different personhood. And I can be exactly what I want to and people are going to judge me on that and they might like and they might not like it, in the university in the campus environment we have a lot of freedom to be who we want to be without a lot of discrimination... There is a group, I believe, at this university, for practically everyone. There really is. It's really hard to say that I can find no one at (this university) or (this city) who is not like me or who doesn't at least appreciate me for who I am...so it's a real comfort. (Ricardo)

Chameleon Effect (variant frequency) was defined as people calling on one part of their identities to adapt to a certain situation with certain people. Participants described drawing on different pieces of their identities at different times:

So then I come from New York, I've been to Dominican Republic, and I learned that Patua that they do. And so I'm like a chameleon, if you're from Argentina I'm speaking to you like you're talking to me. And if somebody from the deep South calls me I'm talkin' South too. That's, I just, and if somebody comes from New York and stays here five minutes, that's it! (Rosa)

Affiliation (variant frequency) was defined as connecting with others who identify as mixed. It is exemplified by the following:

Hmm it's just it was uncomfortable but then when I started to meet a lot of more mixed kids, students, they all experience the same thing. In like both communities are just kind of like, "oh you're not completely one of us like we'll still include you but you're not 
completely one of us," but, I just feel that, mixed people always have that little bit of struggle but it doesn't really affect me personally. It's just something that I go through everyday just as someone else will go through something else based on the color of their skin (Julia)

Growth. The domain of Growth was defined as an increase in psychological or emotional strength or improved circumstances as a result of working through the difficulty. Two categories emerged in Growth: Improved Relationships and Self-Esteem.

Improved Relationships (typical frequency) was defined as positive changes in dealings with other people. The following statements exemplify how participants felt their relationships improved as a result of going through adversities related to being mixed:

And also too just coming from the fact that, my Dad and I, even though we had the basketball thing, we weren't necessarily close as far as talking... But as I grew into a man then we started to kinda talking, more as I got to just understand him more that's what it really came down to. I just got to understand him more, got to really, really, really, really love and appreciate where he came from and then from that, I'm like ya know what, that's just a great. I was like, "Wow, he was about to be in the Soviet Army, holy fuck are you kidding me?" And once I made that connection and I was more open and that just made me more open to the culture, then the good vibrations came, then the good company came, and then it just it just took off from there. (Carlos)

In the category Self-Esteem (variant frequency), a few participants discussed an increase in their overall positive feelings about themselves. Two examples follow:

I think because of (town), it was a surfer town so a lot of the boys were blondehaired and blue-eyed surfers. And ...I just knew when I was younger that I got a lot of attention for having more darker features, and more curvy. More curvy body versus straight up and down and being pale, ya know, and having the darker... I just got a lot more attention. And I started to realize that I was beautiful, not that being white isn't, because it is; but I just started to embrace it. (Michelle)

What would you say was one of the major changes in you that happened? (interviewer) Growth... emotionally, mentally (pause)... Because I went through something that was... really bad, and I came out a lot stronger than I thought I was (Gloria). 


\section{Discussion}

The study contributes to the extant literature on mixed identity from an angle that has rarely been undertaken previously, specifically, resilience in the context of Latinx mixed identity. The findings challenge the negative stereotypes about mixed identity adults and adds to the strengths-based literature for such individuals. Self-identified Latinx mixed participants acknowledged experiencing a range of challenges, articulated how they overcame adversities, and went on to specify the perceived gains from overcoming adversities.

With respect to the challenges they faced, a prominent concern was the pressure felt by most participants due to a discrepancy between their own identities and perceptions by the dominant culture. Although all participants identified as being mixed, many participants reported identifying more with one of their identities than with others, a finding that may be due to external pressures historically faced by mixed individuals to "choose." This finding adds support to the literature indicating that monoracism can lead to feelings of confusion and stress (Jackson et al., 2013; Johnston \& Nadal, 2010) and that mixed individuals may struggle with feeling misunderstood, judged, and/or not fully accepted for who they are, thus feeling forced to choose one identity (Pew Research Center, 2015; Shih \& Sanchez, 2005).

Similarly, a few participants talked in great detail about the degree of overall discrimination they had faced, whether directly or indirectly. While this is, unfortunately, not a different experience from other ethnic minority individuals in U.S. society (Brown et al., 2007; Carter, 2007; Sellers et al., 2006), many of the participants discussed the compounded experience of being discriminated against for each of their identities, and often not being accepted by any of their own identity groups; the latter experience has been termed multiracial discrimination (Giamo et al., 2012). It is possible that this experience is similar to the intragroup marginalization that may be experienced by monoracial or monoethnic individuals (Morgan Consoli et al., 2014), but in this study the mixed identified participants experienced this from multiple groups (i.e., in the theme of Cultural Marginalization). In other words, mixed Latinx adults reported experiencing monoracial discrimination, and also experienced intragroup marginalization from individuals within the Latinx group, leading to perhaps further discrimination and feelings of not belonging to any group. These experiences may have been particularly salient for 
these Latinx mixed adults given current immigration debates and the U.S. sociopolitical climate in general.

In the face of these highlighted difficulties, all participants indicated various processes that helped them overcome adversities and systemic injustices. Participants reported that drawing upon their own cultural values, seeing the connection between their heritage cultures, and finding environments which were diverse or included other mixed people were helpful in prevailing over many of the challenges. Research on resilience in Latinx populations has shown that drawing on one's own cultural values helps in overcoming adversity (Morgan Consoli \& Llamas, 2013). Many participants described particular locations, such as their universities, as places where they felt they fit in and worried less about judgment. This finding, which underscores the role of contexts, corroborates previously highlighted environmental factors such as a positive and supportive culture and helpful external relationships in facilitating resilience (Morgan, 2007), particularly for mixed individuals (Jackson et al., 2013; McCubbin, 2006).

Some participants discussed ways in which they were able to frame being mixed that led to gains, including improvement in interpersonal relationships and increased selfesteem. They discussed these gains as a product of having persevered through the challenges and also, in some cases, felt as if they had grown from the adversity. Though the challenges were characterized by instances in which participants might have felt inferior due to the discrimination they experienced, some participants identified a "silver lining" in their difference and therefore attaining a perspective of strength or benefit.

While in no way minimizing the adversity experiences, overall these participants did report that growth made the challenges more meaningful despite the adversity. This has been exemplified in the literature examining thriving in the face of adversities (Morgan Consoli et al., 2013; Llamas \& Morgan Consoli, 2014; Carver, 1998; O’Leary \& Ickovics, 1994). The particular growth in conceptualization and understanding of mixed identity described by some of the participants in the present study is also similar to the benefit of ethnic pride found in previous studies of Latinx cultural values and resilience (Morgan Consoli et al, 2013), including with mixed Latinx individuals (Jackson et al., 2013).

A significant and corroborating contribution to the strengths-based mixed identity literature is that some participants described mixed identity as fostering an ability to quickly and easily adapt to different cultures and environments. Having the ability to utilize different aspects of a persons' identity can aid in and strengthen various 
interpersonal relationships, or give an individual an advantage in different social situations. This is much like the chameleon experience described by other researchers (Downie et al., 2006; Miville et al., 2005), in which mixed identity is seen as value-added in promoting unique skills that monoracially or ethnically identified individuals may not possess (Binning et al., 2009; Sanchez et al., 2009). The results of the current study therefore echo earlier findings about this specific coping ability by mixed people. It is also worth noting that Latinx values such as familismo were underscored as important factors in coping with adversity (Coohey, 2001; Morgan Consoli et al, 2013), although this needs further exploration.

Participants' accounts exemplified that the self-identified mixed population is often a misunderstood population. Some participants reported that others identified them with one aspect of their heritage, but not others. This created both benefits and challenges for the participants. It often meant that the individual had fewer support systems as they only associated with some of their family or peers depending on identities. Alternatively, they sometimes had more peer groups with whom they could associate and relate. This phenomena may be similar to that of other "hidden identities" that people experience such as a non-visible disability, gender identity, adoption, documentation status, homelessness, religious beliefs, and other, possibly stigmatized, hidden identities depending upon context and circumstances (Doane, 1997; Harter et al., 2005; Newheiser \& Barreto, 2014; Thornton, 1996). Thus, self-identified mixed individuals may indeed feel "mixed" about their identities

\section{Limitations and Future Directions}

Although the current study expands the literature focusing on the strengths of individuals identifying as Latinx mixed, as well as further explicating how mixed identity is experienced, it does so with some limitations. One limitation that surfaced was the difficult determination of whether participants were responding in the manner that they wanted to be seen, or how they actually felt they are seen. This is the case with any construct such as this one that is self-reported and may invoke social desirability (Nederhof, 1985). Future studies could attempt to investigate this distinction more closely by asking about social desirability specifically. Additionally, as mentioned above, there are not many specific places or spaces to find individuals who identify as mixed. This 
contributed to difficulties in recruiting respondents who identified in ways consistent with study criteria.

This study focused specifically on the experiences of mixed Latinx adults who reported having overcome an adversity, therefore being resilient, in order to provide rich, in-depth accounts of the phenomena being studied (Patton, 1990; Polkinghorne, 2005). Future studies could explore mixed Latinx individuals who did not feel they had overcome adversities, to better understand any differences between those who overcome and those who do not within this population. Additionally, this study specifically focused on the mixed Latinx racial and ethnic identities of these individuals. Considering other aspects of identities such as gender or social class and how these identities intersect with mixed racial and ethnic identification would be another important future direction. While we included a range of ages, most participants were in their twenties or thirties with one being 19 years of age and another 64 . Future accounts could be collected from individuals of differing ages for an even greater richness of explication of resilience from differing perspectives. Studying minors was beyond the scope of this study, but may also be worthwhile from a developmental perspective.

Finally, many of the challenges, methods of overcoming, and growth instances described by the participants seemed as if they may be common to any adults of mixed race or ethnicity (Salahuddin \& O'Brien, 2011). In other words, except for some of the specific examples given, it was not always clear that these experiences were because these individuals identified as mixed Latinx, even when participants were asked directly about the role of their identity in overcoming adversity. Future studies could attempt to parse this out more.

\section{Implications of Findings}

The findings from this study can be used in multiple ways within counseling and professional psychology. For example, when working with a client who is ethnically or racially mixed, being aware of the intricacies and complexities of mixed identity as highlighted by this study, as well as the potential outlined strengths, can provide a meaningful framework for interventions. For example, initiating a discussion with one's client about the salience of their differing identities may empower the client and inform the therapist. Multiculturally sensitive conversations that recognize past and present societal discrimination while inquiring about the individual's perceived advantages and 
strengths from this mixed identity are also potentially important for understanding the unique identity of each mixed individual.

The variability within the mixed population and how someone within it selfidentifies highlight the importance of not making assumptions and asking clients directly about how they identify and what this means to them. Since earlier writings on identity (e.g., Cross, 1995; Kim, 2001; Sue \& Sue, 1990) it has been known that a multicultural orientation in psychotherapy includes recognizing and potentially discussing salience for clients of particular identities at particular times (Yakushko et al., 2009). The now burgeoning literature on intersectionality emphasizes open dialogue in psychotherapy and avoidance of specific labeling (American Psychological Association, 2003; Chazin \& Klugman, 2014). Furthermore, this literature underscores the importance of recognizing and conceptualizing multiple identities. Such importance is reflected in this study's findings, where individuals identified with more than one race or ethnicity, and different identities were salient for them at different times.

Such considerations would also be important for psychologists in research or educational settings. For example, understanding the complexities of mixed racial/ethnic identity can inform researchers who may otherwise be tempted to simply use "mixed identity" or "Latinx" as a variable in their studies. The umbrella term includes much cultural variation and for many studies it may be crucial to consider and appropriately reflect these differences. Finally, more specific study of mixed individuals and their unique needs as a quickly growing sector of the U.S. population is warranted. With a large proportion of the U.S. population now identifying as mixed, and the largest of that being Latinx mixed, more nuanced information about their experiences would be quite valuable for interventions and service. 


\section{References}

Abiola, T., \& Udofia, O. (2011). Psychometric assessment of the Wagnild and Young's resilience scale in Kano, Nigeria. BioMed Central Research Notes, 4(1), 509. https://doi.org/10.1186/1756-0500-4-509

American Psychological Association (2003). Guidelines on multicultural education, training, research, practice, and organizational change for psychologists. American Psychologist, 58, 377-402.

Anderson, N. B., Bulatao, R. A., \& Cohen, B. (Eds.). (2004). Racial and ethnic identification, official classifications, and health disparities. www.ncbi.nlm.nih.gov/books/NBK25522/

Binning, K. R., Unzueta, M. M., Huo, Y. J., \& Molina, L. E. (2009). The interpretation of multiracial status and its relation to social engagement and psychological well-being. Journal of Social Issues, 65, 35-49. https://doi.org/10.1111/j.1540-4560.2008.01586.x

Brown, P. M. (1990). Biracial identity and social marginality. Child and Adolescent Social Work, 7, 319-337.

Brown, J. S., Meadows, S. O., \& Elder, G. H., Jr. (2007). Race-ethnic inequality and psychological distress: Depressive symptoms from adolescence to young adulthood. Developmental Psychology, 43(6), 1295-1311. https://doi.org/10.1037/0012-1649.43.6.1295

Carter, R. T. (2007). Racism and psychological and emotional injury: Recognizing and assessing race-based traumatic stress. The Counseling Psychologist, 35(1), 13-105. https://doi.org/10.1177/0011000006292033

Carver, C. S. (1998). Resilience and thriving: Issues, models, and linkages. Journal of Social Issues, 54, 245-266.

Chazin, D., \& Klugman, S. (2014). Clinical considerations in working with clients in the coming out process. Pragmatic Case Studies in Psychotherapy, 10, 132146. https://doi.org/10.14713/pcsp.v10i2.1855

Coohey, C. (2001). The relationship between familism and child maltreatment in Latino and Anglo families. Child Maltreatment, 6, 130-142. https://doi.org/10.1177/1077559501006002005

Cross, W. E., Jr. (1995). The psychology of nigrescence: Revising the Cross model. In J. G. Ponterotto, J. M. Casas, L. A. Suzuki, \& C. M. Alexander (Eds.), Handbook for Multicultural Counseling (pp. 93-122). Sage.

Doane, A. W., Jr. (1997). Dominant group ethnic identity in the United States: The role of "hidden" ethnicity in intergroup relations. The Sociological Quarterly, 38, 375-397.

Downie, M., Mageau, G. A., Koestner, R., \& Liodden, T. (2006). On the risk of being a cultural chameleon: Variations in collective self-esteem across social interactions. Cultural Diversity \& Ethnic Minority Psychology, 12, 527-540. https://doi.org/10.1037/1099-9809.12.3.527

Edwards, L. M., \& Pedrotti, J. T. (2008). A content and methodological review of articles concerning multiracial issues in six major counseling journals. Journal of Counseling Psychology, 55, 411-418. https://doi.org/10.1037/0022-0167.55.3.411

Farley, T., Galves, A., Dickinson, L. M., \& Perez, M. J. D. (2005). Stress, coping, and health: A comparison of Mexican Immigrants, Mexican-Americans, and Non-Hispanic Whites. Journal of Immigrant Health, 7, 213-220. https://doi.org/10.1007/s10903-005-3678-5 
Finch, B. K., \& Vega, W. A. (2003). Acculturation stress, social support, and selfrated health among Latinos in California. Journal of Immigrant Health, 5(3), 109-117. https://doi.org/10.1023/A:1023987717921

Garmezy, N. (1993). Children in poverty: Resiliency despite risk. Psychiatry, 56, 127-136.

Giamo, L. S., Schmitt, M. T., \& Outten, H. R. (2012). Perceived discrimination, group identification, and life satisfaction among multiracial people: A test of rejection-identification model. Cultural Diversity and Ethnic Minority Psychology, 18, 319-328. https://doi.org/10.1037/a0029729

Harter, L. M., Berquist, C., Titsworth, B. S., Novak, D., \& Brokaw, T. (2005). The structuring of invisibility among the hidden homeless: The politics of space, stigma, and identity construction. Journal of Applied Communication Research, 33, 305-327. https://doi.org/10.1080/00909880500278079

Haverkamp, B. E., \& Young, R. A. (2007). Paradigms, purpose, and the role of the literature: Formulating a rationale for qualitative investigations. The Counseling Psychologist, 35, 265-294. https://doi.org/10.1177/0011000006292597

Heppner, P. P., Wampold, B. E., Owen, J., Thompson, M. N., \& Wang, K. T. (2016). Research design in counseling (4th ed.). Thompson Brooks/Cole.

Hill, C. E., Knox, S., Thompson, B. J., Williams, E. N., Hess, S. A., \& Ladany, N. (2005). Consensual qualitative research: An update. Journal of Counseling Psychology, 52(2), 196-205. https://doi.org/10.1037/0022-0167.52.2.196

Hill, C. E., Thompson, B. J., \& Williams, E. N. (1997). A guide to conducting Consensual Qualitative Research. The Counseling Psychologist, 25(4), 517572. https://doi.org/10.1177/0011000097254001

Jackson, K. F. (2012). Living the multiracial experience: Shifting racial expressions, resisting race, and seeking community. Qualitative Social Work, 11, 42-60. https://doi.org/10.1177/1473325010375646

Jackson, K. F., Wolven, T., \& Aguilera, K. (2013). Mixed resilience: A study of multiethnic Mexican American stress and coping in Arizona. Family Relations, 62, 212-225. https://doi.org/10.1111/j.1741-3729.2012.00755.x

Jiménez, T. R. (2004). Negotiating ethnic boundaries: Multiethnic Mexican Americans and ethnic identity in the United States. Ethnicities, 4, 75-97. https://doi.org/10.1177/1468796804040329

Johnston, M. P., \& Nadal, K. L. (2010). Multiracial microaggressions: Exposing monoracism in every-day life and clinical practice. In D. W. Sue (Ed.), Microaggressions and marginality: Manifestation, dynamics, and impact (pp. 123-144). Hoboken, NJ: Wiley.

Joseph, S., \& Maltby, J. (2014). Positive functioning inventory: Initial validation of a 12-item self-report measure of well-being. Psychological Well-Being, 4, 15. https://doi.org/10.1186/s13612-014-0015-6

Kim, J. (2001). Asian American identity development theory. In C. L. Wijeyesinghe \& B. W. Jackson III (Eds.), New perspectives on racial identity development: A theoretical and practical anthology (pp. 67-90). New York University.

Lindenberg, C. S., Solorzano, R. M., Bear, D., Strickland, O., Galvis, C., \& Pittman, K. (2002). Reducing substance use and risky behavior among young, lowincome, Mexican-American women: Comparison of two interventions. Applied Nursing Research, 15, 137-148. https://doi.org/10.1053/apnr .2002 .34141 
Llamas, J. \& Morgan Consoli, M. L. (2012). The importance of Familia for Latino/a college students: Examining the role of familial support in intragroup marginalization. Cultural Diversity \& Ethnic Minority Psychology Journal, 18, 395-403

Luthar, S. S., Cicchetti, D., \& Becker, B. (2000). Research on resilience: Response to commentaries. Child Development, 71(3), 573-575. https://doi.org/10.1111/1467-8624.00168

Market, J. (2010). The changing face of racial discrimination: Hispanics as the dominant minority in the USA: A new application of power-threat theory. Critical Sociology, 36, 307-327. https://doi.org/10.1177/0896920509357526

McCubbin, L. D. (2006). The role of indigenous family ethnic schema on well-being among Native Hawaiian families. Contemporary Nurse, 23, 170-180. https://doi.org/10.1177/0020764006065136

Miville, M. L., Constantine, M. G., Baysden, M. F., \& So-Lloyd, G. (2005). Chameleon changes: An exploration of racial identity themes of multiracial people. Journal of Counseling Psychology, 52, 507-516. https://doi.org/10.1037/0022-0167.52.4.507

Morgan, M.L. (2007) International Comparisons of Resilience in Mexican National and Mexican Immigrant Populations, Dissertation Abstracts International. U.S.A.

Morgan Consoli, M.L., Cabrera, A.P., Llamas, J., Noriega, E., \& Gonzalez, N. (2014). An exploratory study of thriving in Latino/a undergraduate students in the U.S. Revista Interamericana de Psicologia/Interamerican Journal of Psychology, 48, 106-118

Morgan Consoli, M.L., Delucio, K., Noriega, E., \& Llamas, J. (2015). Predictors of resilience and thriving among Latino/a undergraduate students. Hispanic Journal of Behavioral Sciences, 37, 304-318.

Morgan Consoli, M. L., Gonzales, N., Cabrera, A. P., Llamas, J., Lopez, S.A. \& Ortega, S. (2011). Thriving and resilience in the Latino/a population: Intersections and discrepancies. Revista Interamericana de Psicologia/Interamerican Journal of Psychology,45(3), 351-362

Morgan Consoli, M. L. \& Llamas, J. (2013). The relationship between Mexican American cultural values, resilience, and thriving. Journal of Counseling Psychology, 60, 617-624. https://doi.org/10.1037/a0033998

Nederhof, A. J. (1985). Methods of coping with social desirability bias: A review. European Journal of Social Psychology, 15, 263-280.

Negy, C., Klein, J. L., \& Brantley, E. D. C. (2004). Multiracial/ethnic clients: History, models, and clinical implications. In Cross-cultural psychotherapy: Toward critical understanding of diverse clients (pp. 231-246). Bent Tree Press.

Newheiser, A., \& Barreto, M. (2014). Hidden costs of hiding stigma: Ironic interpersonal consequences of concealing a stigmatized identity in social interactions. Journal of Experimental Social Psychology, 52, 58-70. https://doi.org/10.1016/j.jesp.2014.01.002

O'Leary, V. E., \& Ickovics, J. R. (1994). Resilience and thriving in response to challenge: An opportunity for a paradigm shift in women's health. Women's Health, 1(2), 121-142.

Olvera, R. L. Suicidal ideation in Hispanic and mixed-ancestry adolescents (2001). Suicide and Life Threatening Behavior, 31, 416-427. https://doi.org/10.1521/suli.31.4.416.22049 
Patton, M. Q. (1990). Qualitative evaluation and research methods (2nd ed.). Sage.

Pew Research Center (2015). Multiracial in America: Proud, diverse and growing in numbers. Pew Research Center. Retrieved from www.pewsocialtrends.org/2015/06/11/multiracial-in-america

Polkinghorne, D. E. (2005). Language and meaning: Data collection in qualitative research. Journal of Counseling Psychology, 52, 137-145. https://doi.org/10.1037/0022-0167.52.2.137

Romo, R. (2011). Between Black and Brown: Blaxican (Black-Mexican) multiracial identity in California. Journal of Black Studies, 42, 402-426. https://doi.org/10.1177/0021934710376172

Roquemore, K. A., Brunsma, D. L., \& Delgado, D. J. (2009). Racing to theory or retheorizing race? Understanding the struggle to build a multiracial identity theory. Journal of Social Issues, 65, 13-34. https://doi.org/10.1111/j.15404560.2008.01585.x

Rutter, M. (1987). Psychosocial resilience and protective mechanisms. In J. Rolf, A. Masten, D. Cichetti, K. Nuechterlein, \& S. Weintraub (Eds.). Risk and protective factors in the development of psychopathology (pp. 181-214). Cambridge University Press.

Salahuddin, N. M., \& O'Brien, K. M. (2011). Challenges and resilience in the lives of urban, multiracial adults: An instrument development study. Journal of Counseling Psychology, 58, 494-507. https://doi.org/10.1037/a0024633

Sanchez, D. T., Shih, M., \& Garcia, J. A. (2009). Juggling multiple racial identities: Malleable racial identification and psychological well-being. Cultural Diversity and Ethnic Minority Psychology, 15, 243-254. https://doi.org/10.1037/a0014373

Sellers, R. M., Copeland- Linder, N., Martin, P. P., \& Lewis, R. H. (2006). Racial identity matters: The relationship between racial discrimination and psychological functioning in African American adolescents. Journal of Research on Adolescence, 16, 187-216. https://doi.org/10.1111/j.15327795.2006.00128.x

Shih, M., \& Sanchez, D. T. (2005). Perspectives and research on the positive and negative implications of having multiple racial identities. Psychological Bulletin, 131(4), 569-591. https://doi.org/10.1037/0033-2909.131.4.569

Shih, M. \& Sanchez, D.T (2009). When race becomes even more complex: Toward understanding the landscape of multiracial identity and experiences. Journal of Social Issues, 65, 1, 1-11.

Stephan, W. G., \& Stephan, C. W. (2000). An integrated theory of prejudice. In S. Oskamp (Ed.) Reducing prejudice and discrimination (pp. 23-46). Lawrence Erlbaum.

Sue, D. W., \& Sue, D. (1990). Counseling the culturally different: Theory and practice. Wiley.

Thornton, M. C. (1996). Hidden agendas, identity theories, and multiracial people. In M. P. P. Root (Ed.), The multiracial experience: Racial borders as the new frontier (pp. 101-120). Sage

Vasconcelos, J. (1925/1979). The cosmic race/La raza cósmica. California State University.

Vasquez, J. M. (2010). Blurred borders for some but not "others": Racialization, "flexible ethnicity," gender, and third-generation Mexican American identity. Sociological Perspectives, 53(1), 45-71. https://doi.org/10.1525/sop.2010.53.1.45 
Wagnild, G. (2009). A review of the Resilience Scale. Journal of Nursing Measurement, 17, 105-113. https://doi.org/10.1891/1061-3749.17.2.105

Wagnild, G., \& Young, H. M. (1993). Development and psychometric evaluation of the Resilience Scale. Journal of Nursing Management, 1, 165-178.

Williams, E. N., \& Morrow, S. L. (2009). Achieving trustworthiness in qualitative research: A pan-paradigmatic perspective. Psychotherapy Research, 19, 576582. https://doi.org/10.1080/10503300802702113

Yakushko, O., Davidson, M. M., \& Williams, E. N. (2009). Identity salience model: A paradigm for integrating multiple identities in clinical practice. Psychotherapy: Theory, Research, Practice, Training, 46, 180-192. https://doi.org/10.1037/a0016080

Zambrana, R. E., Scrimshaw, S. C. M., Collins, N., \& Dunkel-Schetter, C. (1997). Prenatal health behaviors and psychosocial risk factors in pregnant women of Mexican origin: The role of acculturation. American Journal of Public Health, 87, 1022-1026. 


\section{Appendix}

\section{Appendix 1}

Semi-Structured Interview Questions

Can you please tell me about the difficult event/experience?

Por favor, ¿me puede platicar sobre el evento o la experiencia dificil?

How did you respond/react to the difficult event/experience?

¿Cómo respondió o reaccionó al evento o la experiencia dificil?

(Prompt) How did you feel when this event occurred?

¿Cómo se sintió cuando occurrió esta dificultad?

What did you do to handle the event?

¿Qué hizo para controlar lo que pasó?

(Prompt) How did you resolve the difficult experience?

¿Cómo resolvió la experiencia dificil?

Were there any aspects from your cultural background that especially helped you to resolve the event?

¿Hubo aspectos de su cultura que, sobre todo, le ayudó a resolver el caso?

If so, what features about your background helped? How?

Si es si, ¿qué características de su cultura le ayudaron? ¿Cómo?

Did your cultural/ethnic identity influence your ability to bounce back from the difficult experience?

¿Su identidad étnica/cultural influyó su capacidad de recuperarse de la experiencia difícil?

(Prompt) Did this event impact the way that you view your culture?

Esta experiencia ¿impactó como ve su cultura?

Were there any changes in how you view yourself after the event?

¿Hubo algún cambio en la manera en que usted se ve después de pasar por este evento?

If so, what were these changes?

Si fue así, ¿cuáles fueron los cambios?

(Prompt): How did you change?

¿Cómo cambió usted? 